\title{
Narrative Styles and Narratology Formats in PSAs: Assessing the Effects on Arousal, Attention, and Memory
}

\author{
Kimberly Baker \\ Department of Communication, Alabama State University, USA \\ (iD) 0000-0003-1055-6726
}

\section{Fei Qiao}

School of Journalism and Communication, Guangdong University of Foreign Studies, CHINA

(iD) 0000-0002-5322-4847

jennifer.qf@gmail.com

\section{Shuhua Zhou}

School of Journalism, University of Missouri-Columbia, USA

(iD) 0000-0003-2917-658X sc 22939270500

\begin{abstract}
ARTICLE INFO
Received: 13 June 2019

Accepted: 18 September 2019

Published: 30 September 2019

DOI: https://doi.org/10.29333/ojcmt/5948

ABSTRACT

The following study aims to advance knowledge about the effects of narration and pointof-view formats on attention, arousal, and recall for persuasive messages relayed in public service announcements (PSAs). The experiment combines two frameworks, narratology and valence, to expose subjects to 12 different PSAs concerning the topic of animal abuse. Both psychophysiological data and self-report measures were analyzed to determine if three formats of narratology regarding point-of-view (no vocal POV vs. first-person vs. third-person) with two valences (positive vs. negative) have an effect on arousal, as indicated by skin conductance; attention, as indicated by heart rate and memory, and recall as indicated by a posttest unaided recall. The findings contribute toward understanding the emotional and cognitive effects that stimuli have on arousal, attention, and memory.
\end{abstract}

Keywords: arousal, narrative, PSA, psychophysiological, recall, transportation

\section{INTRODUCTION}

Narrative formats are suggested as an effective means of persuading, in part, because of increased engagement, which may lead to decreased message resistance (see Slater \& Rouner, 2002). Research indicates that the appeal of a story and identification with characters can enhance persuasive attempts, in part, by reducing counterarguments (e.g., Moyer-Gusé, Tchernev, \& Walther-Martin, 2019; Nabi \& Moyer-Gusé, 2012). A related concept to the latter is the point of view (POV) of the story (see Alstiel \& Grow, 2006); that is, in simplistic terms, does a single character tell the story, does the story progress from multiple characters contributing to the tale, or is the viewer positioned as privy to all action as a bystander? Narratology theory proposes that POV can affect involvement levels of the audience through identifying with the choices and actions of characters (Abrams, 1988). For instance, third-person point of view reports events from an outsider's perspective and expresses values and facts in a relatively objective manner, presenting 
the stories before audiences' own eyes. On the other hand, the first-person point of view invites audiences to perceive themselves as a central character in stories, generating higher level involvement. Narratology psychology theory further proposes that narratives can influence cognition regarding the ways people think and form judgments based on their understanding of information and stories (Pemberton \& Aarten, 2017). For example, the elicitation of emotional responses is based on assimilative and accommodative modes. The former schema refers to agreeable responses to a narrator's points, while the latter aims to minimize conflicting emotions against a narrator's perspective. For campaigns of public issues, valence is an additional consideration; that is, whether a message is presented positively, such as pointing out benefits, or negatively, such as focusing on consequences; both of which can affect reactions (Lang, 2000).

The current study considered the effects of point-of-view and valence employed in public service announcements (PSAs) - a communication format similar to ads yet typically with purposes of educating about social issues (Nan, 2008) - on arousal, attention, and recall as measured by psychophysiological responses, including indicators of heart rate, skin conductance, as well as self-report surveys. While numerous studies have compared the effects of negative, neutral, and positive tones, such as fear appeals and beneficial appeals (e.g., Bailey, Wang, \& Kaiser, 2017; Duck, Terry, \& Hogg, 1995; Moyer-Gusé et al., 2019), no known studies have considered valence with POV of anthropomorphized characters. Given that online and social platforms have increased the potential of reaching greater numbers and can address more diverse audiences for persuasive campaigns, understanding how information is perceived and processed remains greatly beneficial for creating effective PSAs.

\section{LITERATURE REVIEW}

The concepts of narration and point of view are established storytelling formats analyzed since early rhetorical studies for their stylistic contributions in literary areas (e.g., McCracken, 1989). Regarding persuasive contexts, both concepts are discussed in advertising textbooks (e.g., Alstiel \& Grow, 2006; Yilmaz, 2019) as important considerations for developing persuasive strategies, especially regarding attempts to encourage emotional bonds between audiences and brands Dessart (2017).Psychological measures provide a fusion of physical and psychological assessments to understand the effects of narrative stimuli on cognition and emotional reactions (e.g., Cacioppo, Tassinary, \& Berntson, 2000; Geiger \& Newhagen, 1993; Gordon, Ciorciari, \& Laer, 2018; Lang, 1994; Ravaja, 2004). The following describes the concepts of narration and POV literature relating to the study, followed by a description of relevant psychophysiological measures.

\section{Narrative Persuasion Theory}

Hinyard and Kreuter (2007) have defined narrative as “...an identifiable beginning, middle, and end that provides information about scene, characters, and conflict; raises unanswered questions or unresolved conflict; and provides resolution" (p. 778). Fisher (1984) has described narrative research as "a theory of symbolic actions, words, and/or deeds that have sequence and meaning for those who live, create, and interpret them" (p. 2). This approach, thus, has provided a framework to study the processes people use for detecting stimuli, encoding messages into mental representations, and recalling information. Researchers have proposed that using narration for persuasive messaging may elicit a greater immersion into a story as compared to messages providing primarily information, with narration resulting in vivid mental stimulation that allows the story to 
be experienced emotionally and cognitively (Johnson, Hashtroudi, \& Lindsay, 1993). Advertisements employing narrative strategies have also been found to increase recall (Brechman \& Purvis, 2015), foster greater emotional connections between customers and brands (Kemp, Borders, Anaza, \& Johnston, 2018), and propel action, such as purchases (Granitz \& Forman, 2015). This storytelling immersion has several important contributing factors, with the concept of transportation as a critical component for this study.

Transportation. The concept of transportation is proposed as a "distinct mental process, an integrative melding of attention, imagery, and feelings" (Green \& Brock, 2000). Gerrig (1993) has described the process as akin to the ways in which travelers journey from an original point to a destination and back, and, in doing so, are changed by the experience. For narration and persuasion studies, the concept of transportation has been proposed as, whether factual or fictional, an effective change agent. This is thought to be in part because of the activation of multiple types of mental and emotional processing as compared to other forms of persuasion lacking in emotional appeals (Green \& Brock, 2000). Research has found narrative to be significantly more effective than numerical information in encouraging greater acceptance of stigmatized groups (Wojcieszak \& Kim, 2016).

Transportation versus cognition. Dual-process models, such as the elaboration likelihood model (ELM; Petty \& Cacioppo, 1981) and the heuristic-systematic model (HSM; Chaiken, 1980), have proposed that individuals can be persuaded through activating cognitive processing. This activation sparks either a high elaboration route called central or systematic route processing in which careful consideration of the information is performed, resulting in long-term storage, or low elaboration route called peripheral or heuristic processing; thus, these processes can create attitude changes based on short-cut processing (Petty \& Cacioppo, 1981). Generally, as described by dual-process models, the optimal way to increase the potential of long-lasting effects is to engage cognitive processing, thus, encouraging new information to be embedded into a person's complex mental schema. This mental process is quite different from what transportation proposes.

Green and Brock (2000) have explained that transportation is not a consideration of the pieces of an argument that can lead to logical evaluations and conclusions; rather, it is an immersion into the story, resulting in past experiences and currently held schemas being temporarily suspended. In other words, disbelief is held for the moment, because the desire to experience the story overrides the desire to analyze information. Thus, a greater willingness to accept information may occur as opposed to being more resistant to ideas that may be in conflict with currently held beliefs. The information, thus, can be viewed as being incorporated within schema based not only on the logical conclusions but emotional reactions as well, which researchers have suggested as more effective for recall (Green \& Brock, 2000). Studies have also shown narrative messages designed to encourage transportation may increase intentions to act, such as reducing risky behaviors relating to skin cancer and increasing healthy behaviors (Dilliard, Ferrer, \& Welch, 2018).

Transportation and the role of characters. Because of the immersion potential of storytelling, Green and Brock (2000) have suggested three ways in which transportation may lead to persuasion: (a) transportation may reduce counterarguments because of a temporary state of suspension; (b) transportation may increase the sense of actually experiencing the story; (c) transportation may enhance feelings toward the characters, resulting in a greater emotional reaction. The roles of characters and the emotional 
connections viewers may develop upon immersing into storytelling may be highly relevant for considering the effectiveness of messaging in public service announcements. Because of the limited time PSAs generally have to relay information, the ability to immediate grab attention and quickly immerse a viewer into storytelling may rely greatly on how quickly the characters are assessed and, thus, are viewed as being connected to the viewer. As Surmelian (1969) has noted in a discussion about literary techniques, the characters are what drive a story. Green and Brock (2000) have stressed that the more highly involved a reader becomes with characters, the more likely the characters may be considered as relevant sources of information. Additionally, research has shown that even audio-only character narration can overcome resistance to narrative persuasion (Semmler \& Loof, 2019). Considering the roles of characters in narration also leads to another important element in considering the effectiveness of persuasive messages in storytelling: the point of view the narration adopts in telling the story and delivering the persuasive information.

\section{Narratology (Point-of-View) Theory}

As Stern (1991) has noted, the consideration of techniques for persuasion, especially regarding advertising, is an important component of communication theory given that the tools used in persuasion involve a source promoting a particular desired effect on the receiver. Stern (1991) has made a distinction, based on literary principles, to discuss firstperson narration (FPN), third-person narration (TPN), and dramatic (non-narrated) characterization (DC) in the context of persuasive advertising. According to Barthes (1974), the varied ways in which presenters relay information can influence viewers' expectations, which can then affect later responses to similar presenters. Thus, the role of POV has been considered a key element in persuasive intents because of this relational encoding possibility (Frye, 1973).

The first-person narrator. The first-person narrator perspective, which is considered the telling of one's own story, using "I" or "we" in some cases, has been proposed as an effective tool for persuading because of its ability to convey emotional messages through candid revelations (Martin, 1986). The sharing of personal values and attitudes is considered a technique to increase credibility through providing what may be considered as an authentic voice (Trilling, 1972). The use of FNP has shown to be effective in affecting attitudes toward messages based on enhancing greater perceived credibility toward characters (Grice, 1989). Kim and Shapiro (2016) found that transportation effects for first-person POV (e.g., the use of "I" and "we") as compared to third-person POV (e.g., the role of an observer being told how characters feel and act) were significantly greater for those identifying as similar with the characters. A study analyzing the effects of POV on persuasive messages in PSAs concerning vaccines also found significant support for greater effects of FNP as compared to third-person POV (Nan, Futerfas, \& Ma, 2017). However, other studies have shown no significant differences (Chen, Bell, \& Taylor, 2016; Nazione, 2016).

Although, Stern (1991) has pointed out that FPN has the drawback of limiting variety in who tells story, PSAs are generally limited to a short time period; thus, multiple points of view may not be as critical as compared to other elements, such as how the viewers perceive the main character as being relatable. Another potential negative of the FPN may also be the potential for the character to be perceived as dislikable or not credible, which is an important consideration for persuasive messages because of potential boomerang effects. For this study, the inclusion of PSAs that use anthropomorphized animal characters in FNP formats offered the opportunity to analyze the effects of what 
generally are considered likeable characters (e.g., dogs) on activation, arousal, and recall. It is possible that the effects may be greater because of increased transportation and connection with characters.

The third-person narrator. The third-person narrator perspective, in which the viewer is experiencing the story from an omniscient position, is a common marketing format for relaying information that has minimal emotional elements (Stern, 1991). In the field of exploring media effects, this perspective can be considered quite optimal for studies analyzing dual-process models, considering a goal is often to have consumers analyze information. When used in literary works, multiple viewpoints can be told and the viewer can be privy to information not known to characters; however, for persuasive messages, an omniscient viewpoint can be more readily perceived as including persuasive messages; thus, counterarguments may occur (Wells, 1989). For public campaigns, this role may work well for topics in which an expert character conveys complex information; however, for PSAs of emotionally charged topics such as animal abuse, this perspective may be perceived as what Stern (1991) describes as too distant and unrealistic. However, it is possible that a threshold may exist in which highly arousing messages may be more effectively conveyed in third-person formats to minimize the potential of viewers tuning out upsetting messages of which they relate when connecting to characters of first-person viewpoints. In comparing attitudes toward stigmatized groups, Christy (2018) found third-person point-of-view narratives to be significantly more effective in encouraging positive attitudes for people within the group, while first-person POV was more effective for those outside of the group. The consideration of the negative or positive tone of persuasive messages being conveyed is an additional factor to consider when analyzing the effectiveness of PSAs.

\section{Valence}

Research considering the valence (e.g., positive, negative, or neutral) of messages with persuasive intent indicates mixed results. Research analyzing fear appeals shows negative messages are less effective when consequences are long-term, such as illness or death (e.g., Collins et al., 1987); however, fear appeals including social consequences, such as being shunned for a bad habit that leads to illness or death, show increased effectiveness (e.g., Beaudoin, 2002). These differences may have a basis in the potential arousing effects of negative messages, especially when combined with personally relevant social appeals (Lang, Park, Sanders-Jackson, Wilson, \& Wang, 2007). A recent study found valence to be significant on attention and reactions when information was presented as either narrative or non-narrative: negative messages were more significantly effective for non-narrative formats while positive messages were more significantly effective for narrative formats (Leshner, Bolls, Gardner, Moore, \& Kreuter, 2018). Based on previous research that has found valence to significantly affect reactions toward messaging (Lang et al., 2007), this study has classified valence as positive or negative within three contexts: events discussed (adopted vs. abandoned animals), location/context (shelters vs. homes), and portrayal of emotions (smiles vs. frowns). Of particular interest for this study was if messages using differing points of view of positive and negative valence affect arousal and recall.

\section{Public Service Announcements as Persuasive Messages}

The use of public service announcements to study various theoretical principles is a common practice in media effects research, as well as persuasive messaging. This study modified the framework of a much-cited study by Duck, Terry, and Hogg (1995) in which researchers employed eleven PSA/advertisements of AIDS to analyze message 
effectiveness. As nonprofit organizations have increased opportunities to reach people through video-sharing sites online throughless expensive techniques, understanding how to create effective PSAs is of importance for public campaigns. Also, the techniques implemented in PSAs provide opportunities for researchers to consider the effects that various formats have on the public. By combining self-report measures with psychophysiological data, this study can lend insights into how people react to persuasive storytelling techniques.

\section{Psychophysiological Measurements}

The use of psychophysiological measurements in the media effects disciplines is an established manner of study dating back decades with a surge of studies since the 1980s. Using heart rate to indicate orienting responses as a measure of tonic cognitive effect and using skin conductance as a measure of arousal has included dozens of studies since the 2000s (e.g., Grabe, Zhou, Lang, \& Bolls, 2000; Lang, Zhou, Schwartz, Bolls, \& Potter, 2000). While these studies have analyzed television and PSAs (e.g., Lang 1990; Lang et al., 2000; Modica et al., 2018; Wang \& Lang, 2012; Zhang, et al., 2016), websites (e.g., Kallinen \& Ravaja, 2007), still photographs (e.g., Codispoti, Ferrari, \& Bradley, 2006), audio (e.g., Bolls, Lang, \& Potter, 2001), and video games (e.g., Lissak, 2018; Schneider, Lang, Shin, \& Bradley, 2004) in relation to ways media are produced (e.g., Lang, Chung, Lee, Schwartz, \& Shin, 2005; Lang et al., 2000), incorporate audio (Dillman Carpentier, \& Potter, 2007), use animation (Lang, Borse, Wise, \& David, 2002), include textual warnings (e.g., Lang, Borse, Wise, \& David, 2002), and other related variables, studies using psychophysiological methods to analyze reactions to PSAs narrative formats while considering POV are not noted, although a similar concept has been considered for POV effects of video games (Schneider et al., 2004).

This study aimed to consider if narrative formats and POV have an effect on orienting responses, which is described as the involuntary physiological and behavioral responses to stimuli (Lang, 1990). The collection of responses that reflect these changes included sensory, such as the eyes, heart rate, and skin temperature (Lang, 1990). By combining these with self-report data, the study provides a more thorough understanding of effects.

\section{Hypotheses}

By considering an established narration technique with points-of-view formats, the acquired knowledge is beneficial for both researchers desiring to expand understanding of media effects and for nonprofit agencies wanting to gain better techniques in crafting effective and persuasive messages concerning public issues. Based on narrative persuasion theory and narratology principles, the expected results would be that a complete storytelling format with a first-person perspective would indicate higher levels of effects. Additionally, the use of anthropomorphized characters demonstrating a firstperson point of view from the animals' perspectives may indicate the highest level of effects. Thus, the following research questions and hypotheses are proposed:

H1: First-person point-of-view formats will result in greater activation effects than narration with third-person or no narration.

H2: First-person point-of-view formats will result in greater arousal effects than narration with third-person or no narration.

H3: First-person point-of-view formats will result in greater recall effects than narration with third-person or no narration.

RQ1: Do first-person point-of-view formats using anthropomorphized characters result in greater activation effects? 
Online Journal of Communication and Media Technologies, 2019

RQ2: Do first-person point-of-view formats using anthropomorphized characters result in greater arousal effects?

RQ3: Do first-person point-of-view formats using anthropomorphized characters result in greater recall effects?

RQ4: Does valence (i.e., positive or negative) affect (a) activation, (b) arousal, and (c) recall?

\section{METHODOLOGY}

Overview

The study employs a $3 \times 2 \times 2$ mixed designed experiment with two independent variables and one within-subject, repeated variable. The two independent variables are POV formats and valence. Point-of-view formats have three levels: anthropomorphized first-person narration, or AFPN, human first-person narration or HFPN, and non-firstperson narration or NFPN. Valence has two levels: negative and positive. The repeated variable was designed to show two similar PSAs in each condition. As such, each participant in the experiment saw a total of 12 PSAs.

\section{Participants}

The opportunity to participate in the study was offered to college students enrolled in communication courses from a university in the U.S. Southeast in adherence with its Internal Review Board. Participants received credit toward a class requirement for participation. Procedures were followed to ensure confidentiality. An information sheet was explained and provided to the participants (see Appendix A).

All participants received the same set of stimuli: twelve public service announcements with an assessment for each following by a PSA assessment surveys for each viewing, with a posttest unaided recall survey. The study took place in a psychophysiological lab equipped with a television and psychophysiological equipment. The primary researchers, who were trained in conducting psychophysiological experiments, distributed materials, gave instructions, conducted the experiment, and collected data. A sample session with a colleague was conducted to test the equipment, procedures, and confirm the estimated time of the study, which was rated as approximately 50 minutes.

\section{Stimuli}

How audiences pay attention to stimuli, receive and process information, respond to and recall information are important for creating effective messages regarding public issues. As many nonprofit organizations operate on limited budgets, understanding how to convey persuasive messages can be critical, especially given the expanded opportunities that video-sharing sites on the Internet provide for increased viewing. Thus, public service announcements were chosen as the stimuli as opposed to commercials (see Appendix B).

The 12 PSAs were segmented into three groups of four based on narrative styles. One group represented narrative persuasion as defined by Hinyard and Kreuter (2007); a second group represented PSAs employing some narrative elements but not a complete story (e.g., characters, conflict, either a beginning, middle or end but not all required elements), and a third group represented messages with no narrative elements, (i.e., base rate information). Within these three groups, each of the four PSAs represented a selection of three specific point-of-view formats based on narratology (i.e., no vocal POV, firstperson, third-person). As mentioned earlier, narratology theory considers the effects that point-of-view techniques may have as a persuasive tool. The theory has considered not just what is being told but the manner in which stories are conveyed (Abrams, 1988).Of 
particular interest is the inclusion of PSAs with a first-person POV from the animal as the character of persuasion.

The PSA stimuli ranged from 30 seconds to 149 seconds (see Appendix A).

\section{Dependent variables}

There are two sets of dependent variables: one, a physiological variable; two, self-report variables.

\section{Physiology variables}

Skin Conductance Response (SCR). To collect SCR, electrodes were placed around the tips of participants' index and middle fingers of their non-dominant hands. SCR level was sensitive to the experiment environment. To ensure accuracy of the SCR data collection, the noise and temperature levels of the environment were controlled throughout the experiment. As stated in the literature review section, SCR is the indicator for arousal. The increase number of SCR indicated the increase level of arousal.

Heart Rate (HR). To collect HR, electrodes were placed around participants' dominant and non-dominant forearms. Similar as SCR, HR was also sensitive to the experiment environment. The noise and temperature levels of the experiment environment were controlled. As stated above, HR is the indicator for attention. The decrease of HR indicated an increased level of attention.

\section{Self-report variables}

Emotional Response. Emotional response was measured by 11 seven-point (e.g., definitely did not feel to over-whelming) check-mark scales (e.g., confused, intrigued, inspired, bored, excited, surprised, angry, disgusted, sad, happy, and motivated) modified by a previous study (Zhou, Xu, \& Ye, 2009; see Appendix B).

Recall. PSA recall was measured as free recall response. The participants were asked to list the PSAs they viewed previously (see Appendix C).

\section{Research Procedures}

The primary researchers greeted participants individually, explained the procedures, and obtained consent for measuring heart rate and skin conductance while watching public service announcements. Using specific procedures designed to conduct psychophysiological experiments, participants were prepped for electrodes and connected to data-collection equipment. Seven electrodes were attached as follows: two on participants' non-dominant hand, two on their non-dominant forearm, one on their dominant forearm, and two above the eyebrow.

The participants watched 12 PSAs with the order randomized after each session. Psychophysiological data were collected throughout the experiment with a series of cues marking the segments of viewing. At the completion of each PSA, participants completed self-report measures of emotional response and attitudes (see Appendix B). After all 12 PSAs were viewed and survey data collected, participants completed a distraction task consisting of watching approximately 10 minutes of television programming recorded from a network channel. Having students complete this task was designed to wipe out short-term memory traces of the PSAs. Following the distraction procedure, participants completed an unaided recall test to assess the information retained from the PSAs (see Appendix C). Upon completion of the recall test, participants were debriefed and thanked.

\section{RESULTS}

Of the potential student pool, a total of 23 participants' psychophysiological data were analyzed. For analyzing the physiological hypotheses, participants' heart rate changes, 
and total number of their skin conductance responses were analyzed. Heart rate change was an indicator for participants' attention levels. The decrease of heart rate indicated the increase of attention. In the study, the score of heart rate change for each clip was the score of average heart rate subtracted from the baseline heart rate. A negative value of heart rate change indicated average heart rate value was smaller than the baseline heart rate, thus, marking the decrease of heart rate. The positive value of heart rate change indicated average heart rate value was larger than the baseline heart rate, thus, marking the increase of heart rate.

A series of two-way repeated measures ANOVA were conducted. Based on the results, a significant main effect of point-of-view formats was found $(F(2,44)=16.877, p<.001)$. The results showed that the human perspective $(M=-2.553, S D=1.445)$ generated the greatest heart rate change than either the animal perspective $(M=1.214, S D=1.454)$ or third-person narration perspective $(M=-1.380, S D=1.530)$. In other words, clips from the human first-person narration generated the greatest attention level. Thus, H1 was supported: First-person point-of-view will result in greater activation effects than narration with third-person or no narration.

While RQ1 found significant differences, an opposite effect occurred than proposed: Do first-person point-of-view formats using anthropomorphized characters result in greater activation effects? While differences were found, the first-person point1of-view format of human characters showed greater activation effects than those of anthropomorphized characters.

Moreover, a significant main effect of negative valence was found $(F(1,22)=10.18$, $p<.05)$. The results showed that positive valence $(M=-1.889, S D=1.444)$ generated greater heart rate change than negative valence $(M=.077, S D=1.474)$ in the video clips. In other words, clips of positive valence generated greater attention levels than clips of negative valence.

Thus, significant differences were found for RQ4a regarding if valence affects attention levels.

In terms of skin conductance responses, the total SCR numbers were analyzed. Based on the results, a significant main effect of point-of-view formats was found $(F(2,44)=$ $10.015, p<.05)$. The results showed that the human perspective generated the highest SCR number $(M=7.5, S D=1.739)$. This finding was consistent with the heart rate change. Therefore, clips from the human perspective generated the highest arousal levels. Thus H2 was supported: First-person point-of-view formats will result in greater arousal effects than narration with third-person or no narration.

While RQ2 found significant differences, an opposite effect occurred than proposed: Do first-person point-of-view formats using anthropomorphized characters result in greater arousal effects? Differences were found, with the first-person point of view of human characters showing greater arousal effects than those of anthropomorphized characters. No significant differences were found for RQ4b regarding if valence affects arousal levels.

For the self-report effects, the two-way repeated measures ANOVA were used. The emotional arousing scores were based on the average score of the 11-point semantic scales. Based on the results, a significant main effect of valence was found $(F(2,22)=4.43$, $p<.05)$. Negative valence $(M=2.62, S D=.129)$ generated greater emotional arousing levels than positive valence $(M=2.31, S D=.177)$. In other words, clips of negative valence were more emotionally arousing than clips of positive valence. No significant main effect of POV was found. 
For the self-report recall level, the two-way repeated measures ANOVA were applied. Based on the results, a significant main effect of POV was found $(F(2,44)=4.44, p<.05)$. Animal perspective $(M=1.26, S D=.137)$ generated the greatest recall rate than either the human perspective $(M=.935, S D=.110)$ or third-person narration $(M=.761$, $S D=.099)$. In other words, clips from the animal perspective were recalled at greater levels than those of the human perspective or no narration. Thus, H3 was supported, with first-person point of view showing significantly higher levels of recall as compared to third-person or no narration. Additionally, RQ3 found significant differences, with firstperson anthropomorphized characters showing greater recall effects than human firstperson POV. No significant differences were found for valence; thus, RQ4c regarding the possibility of anthropomorphized characters showing greater recall effects based on valence was not found.

For the self-report emotional arousing level, the two-way repeated measures ANOVA were used. The emotional arousing scores were based on the average score of the 11-point semantic scales. Based on the results, no significant main effect of POV was found. However, a significant main effect of valence was found $(F(2,22)=4.43, p<.05)$. Negative valence $(M=2.62, S D=.129)$ generated greater emotional arousing level than positive valence $(M=2.31, S D=.177)$. In other words, clips of negative valence were more emotionally arousing than clips of positive valence.

\section{DISCUSSION}

Based on the physiological data, results support the premise that first-person narratives generate the highest levels of arousal and attention. However, anthropomorphized characters did not have greater levels for either when compared to human characters. Public service announcements with human narration generated the greatest attention levels and arousal levels; yet, based on recall measures, participants indicated greater recall for PSAs using anthropomorphized characters, or what can considered as messages portrayed from the animals' perspectives. These findings may seem contradictory but are in line with the limited capacity approach. According to the model's approach, messages with complicated structures or content may trigger high levels of attention but poor memory (Lang et al., 2000). Reasons include the premise that when viewers begin to pay attention to messages, they are concentrating on encoding messages; thus, they may fail to allocate sufficient resources to process and store the messages.

It is possible that participants analyzed persuasive messages from human characters more critically as compared to animal characters based on factors such as identifying or not with the human characters or critiquing the credibility or likeability of the human. Thus, the process of critiquing the person may contribute to greater attention and arousal levels; whereas, animal characters may be more readily accepted. Therefore, information from the latter may be processed without taxing resources to encode and store messages. This finding is consistent to emotional response models stated in narratology theory (Pemberton \& Aarten, 2017). Critiques of human credibility prompt audiences to adopt an accommodative mode to process information. Within accommodative schema, efforts to persuade audiences or have them agree with a narrator's views are more difficult, because audience members need to be exposed to additional evidence or stories to overcome their resistant of their views toward the narrator. On the other hand, the trust of animal characters arouses audiences' empathic responses, allowing them to employ the assimilative mode when receiving messages. Under assimilative schema, audiences are 
easier to persuade and more likely to agree with a narrator's points. Moreover, as Lang et al. (2000) has suggested, the structure and content of messages exert influence on viewers' memories. The results of the current study have shown that when comparing PSAs with animal perspectives, PSAs with human narrations were poorly remembered. This reduction in taxing resources may lead to increased abilities for participants to memorize messages employing anthropomorphized characters.

Also, another noteworthy finding was that based on the physiological data, positive valence generated greater attention levels than those using negative valence; yet, based on the self-report data, participants were more emotionally aroused by negative valence than the positive ones, which is consistent with research Lang et al. (2007) has conducted. Messages with negative valence may generate greater emotional arousal given humans may be naturally attentive to negative news (Lang et al., 2007). On the other hand, the results of this study show that even though the employment of positive valence was able to generate better attention than the negative one, those with positive messages still failed to emotionally arouse the participants or encourage greater recall.

According to the results of the current research, several practical implications are indicated. First, PSAs with first-person animal narrators' perspectives indicate greater recall than any other formats. Using nonhuman characters may more effectively and perhaps more quickly transport and immerse viewers into storytelling situations without prompting analysis of information. This state of being involved with the storytelling from the animals' viewpoints may lead to greater recall through building fewer counterarguments to persuasive messages and connecting with what generally are considered likeable characters. Second, PSAs with negative valence were able to arouse viewers' emotions. The employment of negative valence can lead viewers to be emotionally captivated, thus, may activate a greater variety of emotions. For example, a PSA in which the animal character is initially considered cute (e.g. joyful) yet discusses being abused and abandoned could initiate complex feelings of anger, sadness, helplessness, and others in a relatively short time compared to a positive message of being adopted, which may initiate fewer emotions, such as joy. Lastly, the results of the current study showed that messages generating greater arousal did not necessarily equate to participants demonstrating greater recall. Therefore, when embedding differing points of view or valences, practitioners may need to consider the structure and content of the PSAs for achieving objectives. Based on the limited capacity approach, the complex structure or model needs to be avoided in order to generate better memory for the viewers.

\section{Limitations and Future Research}

While the current study offers a first step in considering how point of view and valence may affect arousal and recall, several limitations should be noted. The findings are based on a small sample size of college students. Future studies need to expand the number of participants and include additional groups for greater generalizability. Another limitation relating to subjects include considering prior exposure to subject matter of the public service announcements. The subject of animal abuse, in part, allowed consideration of a potentially emotional issue but without a situation in which participants would have had experience of actually being a victim. Yet, participants could have differing levels of interest and involvement with the topic, such as being in abusive situations or witnessing abuse; however, prior exposure was not measured.

While care was taken to choose an equal number of stimuli representing the variables analyzed, an additional consideration should be querying participants about prior exposure to individual PSAs. Exposure to previously unseen content may create greater 
arousal than more familiar messages. Additionally, an online view count was not considered when selecting PSAs nor was the number of media channels used. It could be that prior exposure may increase or decrease arousal and recall. Also, the manner of viewing may affect perceptions of the PSAs, meaning that if a participant recalled viewing a PSA on a broadcast channel and online, the PSA could be viewed as more credible or more worthy of analysis as compared to an unfamiliar one.

An additional limitation is only considering two variables: point of view and valence. More elements of the PSAs could be included for analyses. For example, future research should consider the effects of highly arousing emotional music for what are already typically considered highly arousing public topics (e.g., homeless pets, wounded warriors, victims of bullying). It is possible that music has the potential to create such high levels of emotion an adverse reaction occurs (e.g., viewers quit watching). While music was not measured in the study, anecdotal evidence from participants suggests that music in PSAs can evoke sadness (e.g., PSA with Sarah McLachlan song). In such cases, perhaps different combinations of audio and visual may show differing effects. For example, upbeat music with arousing images could increase arousal while lessening the feelings of being overwhelmed, or emotionally charged music could be used with statistical information for increasing the appeal of base rate information. While the PSAs used as stimuli in this study included music, the effects were not specifically analyzed.

\section{CONCLUSION}

This study offers findings supporting that analyzing psychophysiological responses with self-report measures lend important data for understanding ways in which arousal and recall may be enhanced, and, thus, contribute toward both theoretical development and practical applications for achieving campaign objectives. In terms of theoretical development, the current study reinforces that first-person narratives are able to achieve high levels of arousal and attention as well as noting that negative valence is more emotionally arousing than positive valence, which is consistent with limited capacity approach (Lang et al., 2000). In addition, anthropomorphized characters can better stimulate audiences' assimilative schema, exerting better persuasive impacts on viewers than human characters in PSAs. In terms of managerial implications, practitioners can consider incorporating nonhuman characters as a means for encouraging recall or important messages. Additionally, a combination of negative and positive messages with first-person formats may work together to elevate both attention and arousal levels. More research regarding ways in which nonhuman characters and valence are employed in PSAs may lead to greater understanding of effectively crafting persuasive messages.

\section{ACKNOWLEDGEMENT}

We appreciate the constructive comments from the reviewers. Fei Qiao is the corresponding author of this article.

\section{REFERENCES}

Abrams, M. H. (1988). A glossary of literary terms (5 $5^{\text {th }}$ ed.). New York: Hold, Rinehart, and Winston, Inc.

Alstiel, T. and Grow, J. (2006). Advertising Strategy: Creative tactics from the Outside/In. Thousand Oaks, CA: Sage. 
Online Journal of Communication and Media Technologies, 2019

Bailey, R. L., Wang, T. and Kaiser, C. K. (2017). Clash of the primary motivations: Motivated processing of emotionally experience content in fear appeals about obesity prevention. Health Communication, 33(2), 111-121. https://doi.org/10.1080/10410236. 2016.1250186

Bandura, A. (1986). Social Foundations of Thought and Action: A Social Cognitive Theory. Englewood Cliffs, NJ: Prentice-Hall.

Barthes, R. (1974). Introduction to the structural analysis of narratives. London, UK: Collins.

Bolls, P. D., Lang, A. and Potter, R. F. (2001).The effects of message valence and listener arousal on attention, memory, and facial muscular responses to radio advertisements. Communication Research, 28(5), 627-651. https://doi.org/10.1177/ 009365001028005003

Cacioppo, J. T., Tassinary, L. G. and Berntson, G. G. (2000).The handbook of psychophysiology. New York, NY: Cambridge University Press.

Chaiken, S. (1980). Heuristic versus systematic information processing and the use of source versus message cues in persuasion. Journal of Personality and Social Psychology, 39(5), 752. https://doi.org/10.1037/0022-3514.39.5.752

Chen, M., Bell, R. A. and Taylor, L. D. (2016). Narrator point of view and persuasion in health narratives: The role of protagonist-reader similarity, identification, and selfreferencing. Journal of Health Communication, 21, 908-918. https://doi.org/10.1080/10810730.2016.1177147

Christy, K. R. (2018). I, You, or He: Examining the Impact of Point of View on Narrative Persuasion. Media Psychology, 21(4), 700-718. https://doi.org/10.1080/15213269. 2017.1400443

Codispoti, M., Ferrari, V. and Bradley, M. M. (2006). Repetitive picture processing: autonomic and cortical correlates. Brain Research, 1068(1), 213-220. https://doi.org/10.1016/j.brainres.2005.11.009

Dessart, L. (2017). Social media engagement: A model of antecedents and relational outcomes. Journal of Marketing Management, 1-25. https://doi.org/10.1080/ 0267257X.2017.1302975

Dilliard, A. J., Ferrer, R. A. and Welch, J. D. (2018).Associations between narrative transportation, risk perception and behavior intentions following narrative messages about skin cancer. Psychology and Health, 33(5), 573-593. https://doi.org/10.1080/08870446.2017.1380811

Dillman Carpentier, F. R. and Potter, R. F. (2007). Effects of music on physiological arousal: Explorations into tempo and genre. Media Psychology, 10(3), 339-363. https://doi.org/10.1080/15213260701533045

Duck, J. M., Terry, D. J. and Hogg, M. A. (1995). The perceived influence of AIDS advertising: Third-person effects in the context of positive media content. Basic and Applied Social Psychology, 17(3), 305-325. https://doi.org/10.1207/s15324834basp170 3_2

Fisher, W. R. (1984). Narration as a human communication paradigm: The case of public moral argument. Communications Monographs, 51(1), 1-22. https://doi.org/10.1080/03637758409390180

Frye, N. (1973). Anatomy of criticism: Four essays. Princeton: Princeton University Press.

Geiger, S. and Newhagen, J. (1993). Revealing the black box: Information processing and media effects. Journal of Communication, 43(4), 42-50. https://doi.org/10.1111/j.14602466.1993.tb01303.x 
Gerrig, R. J. (1993). Experiencing narrative worlds: On the psychological activities of reading. New Haven, CT: Yale University Press.

Gordon, R., Ciorciari, J. and Laer, T. (2018).Using EEG to examine the role of attention, working memory, emotion, and imagination in narrative transportation. European Journal of Marketing, 52(1/2), 92-117. https://doi.org/10.1108/EJM-12-2016-0881

Grabe, M. E., Zhou, S., Lang, A. and Bolls, P. D. (2000). Packaging television news: The effects of tabloid on information processing and evaluative responses. Journal of Broadcasting \& Electronic Media, 44(4), 581-598. https://doi.org/10.1207/s15506878jobem4404_4

Granitz, N. and Foreman, H. (2015).Building self-brand connections: Exploring brand stories through a transmedia perspective. Journal of Brand Management, 22(1), 3859. https://doi.org/10.1057/bm.2015.1

Green, M. C. and Brock, T. C. (2000). The role of transportation in the persuasiveness of public narratives. Journal of Personality and Social Psychology, 79(5), 701. https://doi.org/10.1037/0022-3514.79.5.701

Grice, H. P. (1989). Studies in the way of words. Cambridge, MA: Harvard University Press.

Hinyard, L. J. and Kreuter, M. W. (2007).Using narrative communication as a tool for health behavior change: A conceptual, theoretical, and empirical overview. Health Education \& Behavior, 34, 777-792. https://doi.org/10.1177/1090198106291963

Johnson, M. K., Hashtroudi, S. and Lindsay, D. S. (1993). Source monitoring. Psychological Bulletin, 114(1), 3-28. https://doi.org/10.1037/0333-2909.114.1.3

Kallinen, K. and Ravaja, N. (2007).Comparing speakers versus headphones in listening to news from a computer-individual differences and psychophysiological responses. Computers in Human Behavior, 23(1), 303-317. https://doi.org/10.1016/j.chb.2004.10. 014

Kemp, E. A., Borders, A. L., Anaza, N. A. and Johnston, W. J. (2018). The heart in organizational buying: Marketer's understanding of emotions and decision-making of buyers. Journal of Business \& Industrial Marketing, 33(1), 19-28. https://doi.org/10.1108/JBIM-06-2017-0129

Kim, H. K. and Shapiro, M. A. (2016). When bad things happen to a protagonist like you: The role of self in resistance to negatively framed health narratives. Journal of Health Communication, 21, 1227-1235. https://doi.org/10.1080/10810730.2016.1240268

Lang, A. (1990). Involuntary attention and physiological arousal evoked by structural features and emotional content in TV commercials. Communication Research, 17(3), 275-299. https://doi.org/10.1177/009365090017003001

Lang, A. (1994). What can the heart tell us about thinking? In Lang, A. (Ed.), Measuring psychological responses to media messages (pp. 99-111). Hillsdale, NJ: Erlbaum. https://doi.org/10.1177/0093650202029003001

Lang, A., Borse, J., Wise, K. and David, P. (2002). Captured by the World Wide Web: Orienting to structural and content features of computer-presented information. Communication Research, 29(3), 215-245. https://doi.org/10.1207/S1532785XMEP07 04_6

Lang, A., Chung, Y., Lee, S., Schwartz, N. and Shin, M. (2005). It's an arousing, fast-paced kind of world: The effects of age and sensation seeking on the information processing of substance-abuse PSAs. Media Psychology, 7(4), 421-454. https://doi.org/10.1207/s15506878jobem4401_7 
Lang, A., Zhou, S., Schwartz, N., Bolls, P. D. and Potter, R. F. (2000). The effects of edits on arousal, attention, and memory for television messages: When an edit is an edit can an edit be too much? Journal of Broadcasting \& Electronic Media, 44(1), 94-109.

Leshner, G., Bolls, P., Gardner, E., Moore, J. and Kreuter, M. (2018). Breast cancer survivor testimonies: Effects of narrative and emotional valence on affect and cognition. Cogent Social Sciences, 4(1). https://doi.org/10.1080/23311886.2018. 1426281

Lissak, G. (2018). Adverse physiological and psychological effects of screen time on children and adolescents: Literature review and case study. Environmental Research, 164, 149-157. https://doi.org/10.1016/j.envres.2018.01.015

Martin, W. (1986).Recent theories of narrative. Ithaca: Cornell University Press.

McCracken, G. (1989). Who is the celebrity endorser? Cultural foundations of the endorsement process. Journal of Consumer Research, (16), 310-321. https://doi.org/10.1086/209217

Modica, E., Rossi, D., Cartocci, G., et al. (2018). Neurophysiological profile of antismoking campaigns. Computational Intelligence and Neuroscience 2018. https://doi.org/10.1155/2018/9721561

Moyer-Gusé, E. (2008). Toward a theory of entertainment persuasion: Explaining the persuasive effects of entertainment-education messages. Communication Theory, 18(3), 407-425. https://doi.org/10.1111/j.1468-2885.2008.00328.x

Moyer-Gusé, E., Chung, A. H. and Jain, P. (2011).Identification with characters and discussion of taboo topics after exposure to an entertainment narrative about sexual health. Journal of Communication, 61(3), 387-406. https://doi.org/10.1111/j.14602466.2011.01551.x

Moyer-Gusé, E., Tchernev, J. M. and Walther-Martin, W. (2019). The persuasiveness of a humorous environmental narrative combined with an explicit persuasive appeal. Science Communication, 41(4), 422-441. https://doi.org/10.1177/1075547019862553

Nabi, R. L. and Moyer-Guse, E. (2012).The psychology underlying media-based persuasion. The Oxford Handbook of Media Psychology (pp. 1-34). https://doi.org/10.1093/oxfordhb/9780195398809.013.0016

Nan, X., Futerfas, M. and Ma, Z. (2017). Role of narrative perspective and modality in the persuasiveness of public service announcements promoting HPV vaccination. Health Communication, 33, 320-328. https://doi.org/10.1080/10410236.2016.1138379

Nazione, S. (2016). An investigation of first- versus third-person risk narrative processing through the lens of the heuristic-systematic model. Communication Research Reports, 33, 145-151. https://doi.org/10.1080/08824096.2016.1155048

Pemberton, A. and Aarten, P. G. (2017). Narrative in the study of victimological processes in terrorism and political violence: An initial exploration. Studies in Conflict and Terrorism, 1-16. Retrieved from http://www.tandfonline.com/doi/pdf/10.1080/ 1057610X.2017.1311110? needAccess=true

Petty, R. E. and Cacioppo, J. T. (1986).The elaboration likelihood model of persuasion. In Berkowitz, L. (Ed.), Advances in experimental social psychology, vol. 19, (pp. 123-205). New York: Academic Press. https://doi.org/10.1016/S0065-2601(08)60214-2

Ravaja, N. (2004). Contributions of psychophysiology to media research: Review and recommendations. Media Psychology, 6(2), 193-235. https://doi.org/10.1207/s1532785 xmep0602_4 
Schneider, E., Lang, A., Shin, M. and Bradley, S. (2004). Death with a story: How story impacts emotional, motivational, and physiological responses to first-person shooter video games. Human Communication Research, 30(3), 361-375. https://doi.org/10.1093/hcr/30.3.361

Semmler, S. M. and Loof, T. (2019).Audio-only character narration overcoming resistance to narrative persuasion. Communication Research Reports, 36(3), 191-200. https://doi.org/10.1080/08824096.2019.1598855

Slater, M. D. and Rouner, D. (2002). Entertainment-education and elaboration likelihood: Understanding the processing of narrative persuasion. Communication Theory, 12(2), 173-191. https://doi.org/10.1111/j.1468-2885.2002.tb00265.x

Stern, B. B. (1991). Who talks advertising? Literary theory and narrative "point of view." Journal of Advertising, XX(3), 9-22. https://doi.org/10.1080/00913367.1991.10673344

Surmelian, L. (1969). Techniques of fiction writing. Garden City, NY: Anchor Books.

Trilling, L. (1972). Sincerity and authenticity. Cambridge, MA: Harvard University Press.

Wang, Z. and Lang, A. (2012). Reconceptualizing excitation transfer as motivational activation changes and a test of the television program context effects. Media Psychology, 15, 68-92. https://doi.org/10.1080/15213269.2011.649604

Wojcieszak, M. and Kim, N. (2016). How to improve attitudes toward disliked groups: The effects of narrative versus numerical evidence on political persuasion. Communication Research, 43, 785-809. https://doi.org/10.1177/0093650215618480

Yilmaz, R. (2019). Handbook of research on narrative advertising. Hershey, PA: ICI Global. https://doi.org/10.4018/978-1-5225-9790-2

Zhang, J., Chen, G. M., Chock, T. M., Wang, Y., Ni, L. and Schweisberger, V. (2016).A psychophysiological study of processing HIV/AIDS public service announcements: The effects of novelty appeals, sexual appeals, narrative versus statistical evidence, and viewer's sex. Health Communication, 31(7), 853-862. https://doi.org/10.1080/ 10410236.2015.1012629 


\section{APPENDIX A}

\section{Descriptions and Links to PSAs}

First-person narration:

1. First-person narration with complete story (animal's perspective): "Ditched" - A humorous PSA with a storyline of a dog talking about his owner being a jerk for dropping him off on the side of the road. Length: 31 seconds https:/youtu.be/zZN76BuM2TA

2. First-person narration with complete story (owners' perspectives): "Meet Our Pet" - Couple shares their story about their adopted pet. Length: 149 seconds. https://www.youtube.com/watch?v=h8c7W-uBkaY\&list=UUqghTD6Xlf24pByTrwqijtw

3. First-person narration with partial story (animal's perspective) "I Know (Natalie Morales)" - Cute PSA about an adopted dog who tells talks to the audience about her owner's odd (people) habits. Length: 31 seconds http://youtu.be/5z6pNxz0EHY

4. First-person narration with partial story (animals' perspectives) "Peace for Dogs" - An unusual approach of having dogs tell about their difficult lives with varying voices that match their appearances. No end of story. Length: 31 seconds http://youtu.be/iG6dAnIMDys

Third-person (omniscient) vocal narration:

5. Third-person narration with complete story: "Mark Buerhrle" - Uses story of baseball player and service dog to encourage adoption. https://www.youtube.com/watch?v=J78rBuvQnbU

6. Third-person narration with partial story: "Meet Your Shelter Pet Today" - Voice-over that shows dogs wanting to meet someone. https://www.youtube.com/watch? $\mathrm{v}=841 \mathrm{CZkxjBU0 \& list}$ $=$ UUqghTD6Xlf24pByTrwqijtw

7. Third-person narration with no story. "Sarah McLachlan" - Singer urging people to adopt with music. Length: 120 seconds. https://www.youtube.com/watch?v=9gspElv1yvc

8. Third-person narration with no story. "CBS Cares" - Still photographs with short narration. Length: 30 seconds._https://youtu.be/Jj5AL1iuveA

No vocal narration (information and visuals only and/or unrelated voices in the background)

9. No vocal narration with complete story. "Sid" - Adopted dog's story is told through visuals and text. Length: 30 seconds. https://www.youtube.com/watch?v=eoRUn8kDlAQ

10. No vocal narration with partial story. "Unconditional love": - Short visual stories of three people who have a rough day and are greeted by dogs at end of day. Length: 95 seconds. https://www.youtube.com/watch?v=nEk_CgJEx6U

11. No vocal narration with partial story. "WSPA and SPCA" - Animated clip of paper animals being treated badly. Length: 70 seconds. https://www.youtube.com/watch?v=ctFXR7s6E6E

12. No vocal narration with no story. "This is Who We Are" - Still photographs with an overlay of textual facts, set to upbeat music. Length: 31 seconds https://www.youtube.com/watch?v= A2stbxtsOy0 


\section{APPENDIX B}

\section{PSA Assessment Survey}

For the PSA that you just watched, please indicate your thoughts for the following statements by circling or highlighting your choice for each (1=strongly disagree, $7=$ strongly agree). For number 9 , please provide your reaction.

\begin{tabular}{cccccccc}
\hline & $\begin{array}{c}\text { Definitely } \\
\text { did not feel }\end{array}$ & $\begin{array}{c}\text { Maybe } \\
\text { a little }\end{array}$ & $\begin{array}{c}\text { Somewhat } \\
\text { felt }\end{array}$ & Definitely & Strongly & $\begin{array}{c}\text { Very } \\
\text { Strongly }\end{array}$ & $\begin{array}{c}\text { Over- } \\
\text { whelming }\end{array}$ \\
\hline Confused & 1 & 2 & 3 & 4 & 5 & 6 & 7 \\
\hline Intrigued & 1 & 2 & 3 & 4 & 5 & 6 & 7 \\
\hline Inspired & 1 & 2 & 3 & 4 & 5 & 6 & 7 \\
\hline Bored & 1 & 2 & 3 & 4 & 5 & 6 & 7 \\
\hline Excited & 1 & 2 & 3 & 4 & 5 & 6 & 7 \\
\hline Surprised & 1 & 2 & 3 & 4 & 5 & 6 & 7 \\
\hline Angry & 1 & 2 & 3 & 4 & 5 & 6 & 7 \\
\hline Disgusted & 1 & 2 & 3 & 4 & 5 & 6 & 7 \\
\hline Sad & 1 & 2 & 3 & 4 & 5 & 6 & 7 \\
\hline Happy & 1 & 2 & 3 & 4 & 5 & 6 & 7 \\
\hline Motivated & 1 & 2 & 3 & 4 & 5 & 6 & 7 \\
\hline
\end{tabular}

\section{APPENDIX C}

\section{Recall Assessment Survey}

Please fill out the following concerning the 12 PSAs that you watched earlier.

1. Please describe in a short phrase or sentence the PSA you remember most clearly and why:

2. Please try to list any of the remaining PSAs that you remember and any details about each:

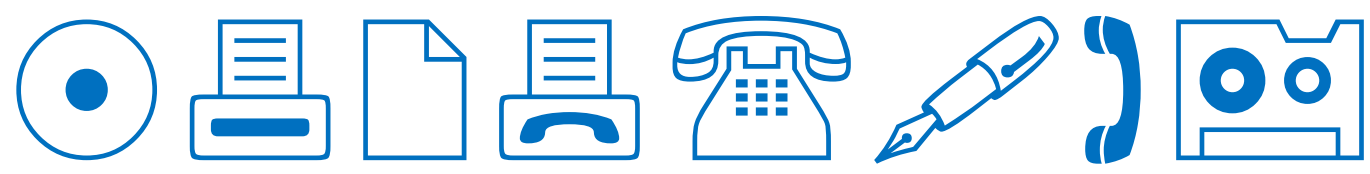

